\title{
Orofacial Human Bite: A Six Year Review of Cases from Komfo Anokye Teaching Hospital
}

\author{
Alexander Oti Acheampong1, Mohammed Duah², Richard Selormey³, Peter Donkor2, \\ Daniel Bankas ${ }^{3}$ \\ ${ }^{1}$ Dental School, Kwame Nkrumah University of Science and Technology, Kumasi, Ghana \\ ${ }^{2}$ School of Medical Sciences, Kwame Nkrumah University of Science and Technology, Kumasi, Ghana \\ ${ }^{3}$ Komfo Anokye Teaching Hospital, Kumasi, Ghana \\ Email: aotiacheampong@yahoo.com
}

Received 8 July 2016; accepted 26 August 2016; published 29 August 2016

Copyright (C) 2016 by authors and Scientific Research Publishing Inc.

This work is licensed under the Creative Commons Attribution International License (CC BY).

http://creativecommons.org/licenses/by/4.0/

(c) (i) Open Access

\begin{abstract}
Background: The orofacial region of the human body is usually not protected during a fight, making it prone to several injuries including human bite. Patients with human bite injury are often either intoxicated or are known to their assailant, and this makes the process of obtaining a reliable history especially about the aetiology difficult. In 2002, a study estimated the rate of infection secondary to human bite to be about $10 \%$. Aim/Objective: The aim of the current study was to have a general overview of orofacial human bites seen at our unit including the aetiology, presentations, anatomic location, treatment and the treatment outcome. Results: Total number of cases was 127 over the six year period. Age range for females was 15 - 61 years with an average of 29.9. Age range for males was from 17 to 60 years and an average of 30.2 years. There were 31 males and 96 females, giving a male to female ratio of approximately 1:3. All of the reported cases resulted from a fight. Most of the offenders are known to the patients. Majority of the cases, except those infected at the time of presentation, were treated on the same day of presentation under local anaesthesia. Relationship of victim to the offender: Spouse/sexual partners were 21, rivals formed 70, known persons to the victim were 26 and strangers were 10 . Sex distribution of offenders and victims: Females who bit females were 86 followed by females who bit males (24), males who bit females (10) and males who bit males (7). Conclusion: Most of the offenders are known to the patients. Majority of the cases, except those infected at the time of presentation, were treated on the same day of presentation under local anaesthesia after they had received antibiotics and anti-tetanus prophylaxis. Early repair is now the recommended mode of treatment for human bites of the orofacial region, accompanied with good oral hygiene instructions and broad spectrum antibiotics and metronidazole.
\end{abstract}

\section{Keywords}

Human Bite, Orofacial, Assault, Lip, Nose

How to cite this paper: Acheampong, A.O., Duah, M., Selormey, R., Donkor, P. and Bankas, D. (2016) Orofacial Human Bite: A Six Year Review of Cases from Komfo Anokye Teaching Hospital. Open Journal of Stomatology, 6, 179-184. 


\section{Introduction}

Orofacial region is made up of the face, eyes, nose, lips and the ears. This region of the human body is usually not protected during a fight making it prone to several injuries including human bite. Studies have shown that human bites are more common among males [1] with the peak incidence between 18 and 78 years according to Merchant et al. [2]. In a study of 388 patients with human bite by Merchant et al. [2], 76.2\% of patients presented to emergency within 12 hrs of injury [2]. This finding is however contrary to a similar study conducted in Ghana where victims of human bite usually presented during the first two days of the injury [1]. Patients with human bite injury are often either intoxicated [2] or are known to their assailant [1] making the process of obtaining a reliable history especially about the aetiology difficult. In 2002, a study estimated the rate of infection secondary to human bite to be about $10 \%$ Perron et al. [3]. This value however is expected to be high in sub-Saharan Africa because of the delay in presentation.

Human saliva is known to contain as many as 50 species of bacteria with almost $100^{6}$ microbes per $\mathrm{ml}$ [3]. In 2003, a multicenter study of infected human bite showed aerobic species were isolated in $44 \%$ of the cases, anaerobic species were isolated in $2 \%$ of cases and both aerobic and anaerobic were isolated in $54 \%$ of the cases Talan et al. [4]. Isolated cases of viral hepatitis, herpes virus, Actinomyces and Treponema pallidum have been reported in the literature [5] [6]. However, HIV transmission is very low due to salivary inhibitors which render the virus non-infective in the majority of cases, Richman et al. [7]. Moreover, transmission of HIV is a risk when there is blood in the mouth of the assailant, and when there's a breach in the skin of the victim Smoot et al. [8]. There have also been reports of necrotizing fasciitis occurring after human bite Sikora et al. [9] and Weinert et al. [10]. Suspicious bite wound should be photographed next to a ruler, a thorough skin examination should be carried out and appropriate consultation should be made Ball et al. [11]. As demonstrated by Staiano et al. [12] in 2007, retained fragments of teeth in the wound has been proven to be dangerous; hence every attempt must be made to rule out the presence of foreign bodies in the bite wounds Staiano et al. [12]. Tetanus immunoglobulin and toxoid is recommended in patients with a history of two or fewer tetanus immunizations Morgan et al. [13].

In 2000, Chen et al. [14] proposed that since human bites are highly contaminated wounds, early primary closure of bite wounds is associated with high rate of infection. However, Donkor et al. studied 30 patients who presented with human bite of the face and noted that a thorough debridement followed by primary closure, direct suturing, a local flap or skin grafting on the day of presentation resulted in 90\% complete wound healing [1]. The aim of the current study was to have a general overview of orofacial human bite seen at our unit to know about the aetiology, presentations, anatomic location, treatment and the treatment outcome.

\section{Methodology/Statistics}

This was a retrospective study. Medical records of all consecutive patients seen during the six year period (2009 to 2014) were reviewed. At the time of the data collection, ethical approval was sort from the head of department of the oral and maxillofacial surgery unit. All patients had a history of human bite. Information gathered from their medical records included age, sex, occupation, who bit the patient, location of bite and the relationship with the suspected offender. Treatment and treatment outcome after two months were also evaluated. The information was decoded to avoid and identify variables. Cleaned data from excel was exported into SPSS II for descriptive analysis.

\section{Results}

Total number of cases was 127 over the six year period. Age range for females was 15 - 61 years with an average of 29.9. Age range for males were from 17 to 60 years, with an average of 30.2 years. Male were 31 and 96 females, given a male to female ratio of approximately 1:3. All of the reported cases resulted from a fight. Females who bit females were "86 (67.8\%)", followed by Females who bit males "41 (18.9\%)", Males who bit females were "10 (7.9\%)" and males who bit males form " $7(5.5 \%)$ ". Traders "67 (52.8\%)" form the majority, followed by unemployed persons "34 (26.8\%)" and Artisans "26 (20.5\%)". 84.7\% of cases presented on the day of injury. In terms of anatomic location of the injury, the lower lip is commonly affected followed by the upper lip. "12 (10.0\%)" presented five days after the injury (mostly infected and offensive). 1A total of "110 (87.0\%)" had primary closure after thorough wound debridement, IV antibiotics stat dose followed by broad spectrum oral antibiotics for one week and also regular warm saline mouth rinse and tooth brushing. Appropriate analgesics and soft diet for one week was also recommended. $6.9 \%$ had local pedicle flaps to help achieve adequate closure 
and cosmetic results. 12) developed hypertophic scar and keloid which were successfully managed with intra lesional injection of kenalog (Triamcinolone). All patients had satisfactory function and aesthetically pleasing appearances after treatment.

\section{Discussion}

Human bite in the orofacial region is a common occurrence especially in most developing countries. In this present study it was seen that more females were affected. The male to female ratio was 1:3. This finding was different from an earlier study by Donkor [1] and Olaitan et al. [15] where there were more male victims than females. In terms of the age distribution, it ranged from adolescence to old age with an average age of 29.9 years for females and 30.2 years for males. This current study is slightly different from Enugu where the male to female was 1:2. This average age is critical in terms of facial cosmetics and acceptance in the society. Because of this, any disfiguring injury of the face is of a major concern to the victim. This disfiguring facial appearance (Figure 1) can affect marital relationship and productivity at work places. In terms of anatomic location of the injury, the lower lip (Figures 1-3) was commonly affected followed by the upper lip (Figure 4) as also shown in Table 1. This finding is different from Olaitan [15], which reported the upper lip to be the commonest site for the injury. The tongue was the least structure affected. All of the patients were involved in a scuffle, and this finding is similar to a study done in Enugu State [15], Nigeria.

Spouse/sexual partners were $16.5 \%$, Rivals form $55.1 \%$. This study demonstrated that most of the offenders and the victims were rivals. This finding is similar to a study done at Obukwe [16] series in Nigeria which attributed polygamous relationship to the cause of assault. Known persons to the patients accounted for $70.5 \%$ and strangers were $29.5 \%$ in this study. This finding is similar to a related study in Nigeria. In that study, 54 patients

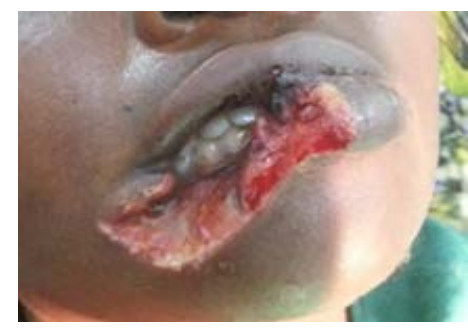

Figure 1. Picture showing disfiguring human bite of the lower lip.

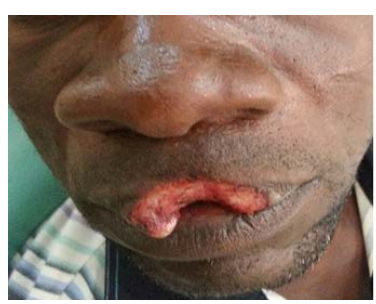

(a)

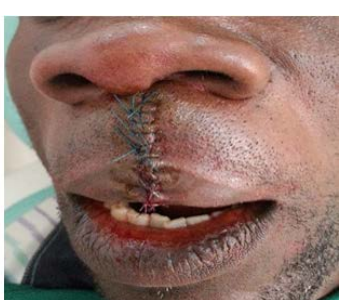

(b)

Figure 2. Picture showing human bite of the upper lip before and after surgery. (a) Before surgery; (b) after surgery (immediately) under local anaesthesia.

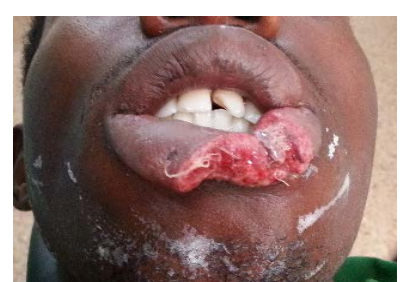

(a)

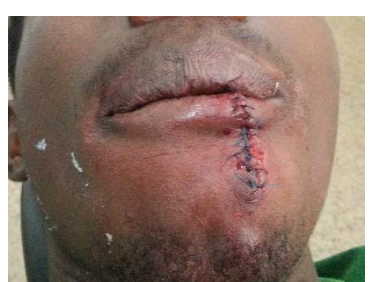

(b)

Figure 3. Picture showing human bite of the lower lip before and after surgery. (a) Before surgery; (b) after surgery (immediately) under local anaesthesia. 


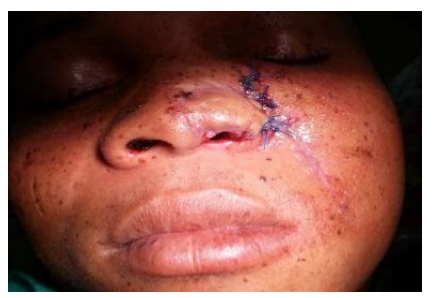

(a)

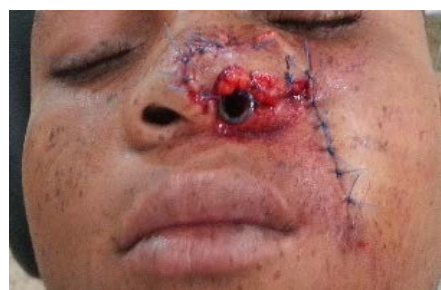

(b)

Figure 4. Picture showing left nasobalia flap to repair human bite of Ala of the nose. (a) Before surgery; (b) after surgery (1 week) under local anaesthesia.

Table 1. Distribution of anatomic location.

\begin{tabular}{cc}
\hline Anatomic location & Number of cases \\
\hline Lower lip & 95 \\
Upper lip & 16 \\
Nose & 7 \\
Ear & 8 \\
Tongue & 1 \\
\hline
\end{tabular}

were seen and out of the number, 92.4\% of the assailants were known to the patients including husbands, wives and sister-in-laws. This finding is also comparable with Datubo-Brown [17] and Obukwe [16] series. Even though it was reported that sexual partners were involved in this disfiguring bites, there were no reported cases of passionate lovebite, clinical vampirism or cannibalism.

Empirical evidence in Ghana shows that our customary marriages are potentially polygamous. This creates rivalry among the women involved who easily engage in fight with the least provocation. In our view, the reason why they prefer to bite on the face is to disfigure the victim and create psychological stress.

Females who bit females were in the majority (67.7\%) followed by females who bit males (18.9\%). The finding in this study demonstrates that more females bit other females. Our study showed that more of the offenders were females, which is also different to the study done in Enugu State [15], Nigeria which gave a male to female ratio in terms of assailants to be $0.6: 1$. In another study from Nigeria, women formed the larger number of the patients and the offenders [16].

There was no case where a patient planned to seek legal redress after the bite injury in our study this could be due to the fact that most of the assailants are known members of the community of even family members, so elders may be consulted to bring amicable solutions to maintain family cohesion. Even though there was no intention of any of our patients to seek legal redress, we suggest that taking pre-operative pictures is mandatory for these patients, as has been previously documented. Traders were in the majority, followed by unemployed persons and artisans. In this present study, even though the study did not evaluate the educational background of the victim and the patients, the above occupations of the patient was an indication that, they may belong to the low socioeconomic class. This finding is different from Datubo-Brown [17] study which reported that most of his patients were semi-illiterate adult females in their third decades and cut across all the socio economic classes similar to Olaitan [15] study. A bout $84.7 \%$ of cases presented during the first two days of the injury. Only $10.0 \%$ presented to the clinicfive days or more after the injury (mostly infected and offensive). This is different from the Enugu study where the average time of presentation being 52 days. The reason why in our present study patients presented early could be due to the fact that, they know our facility is noted for early repair of human bites. This we believe could be due to the awareness created in the media to encourage the public to report early to the hospital for all health related conditions including human bites.

Donkor and Bankas [1], studied 30 patients who presented with human bites of the face and noted that a thorough debridement of the injury, followed by primary closure; direct suturing, local flap, or skin graft on the day of presentation resulted in $90 \%$ complete wound healing. Majority of our patients had primary closure after thorough wound debridement, IV antibiotics stat dose followed by broad spectrum oral antibiotics for one week. Regular warm saline mouth rinse and tooth brushing was always recommended. Appropriate analgesic and soft diet for one week was also advised. Some (6.9\%) of our patients had local pedicle flaps to help achieve adequate 
closure and cosmetic results. In this present study, all injuries were thoroughly debrided before surgical repair. The surgical repairs involved V-shaped wedged excision (70.0\%) (Figure 2 and Figure 4), a nasolabial flap (15.0\%) (Figure 3), midline forehead flap (10.0\%) and Abbe's flap (5.0\%). If the injury is more than 48 hrs and is heavily infected, it is normally debrided and dressed with normal saline. Patient is also given a stat dose of appropriate antibiotics and metronidazole intravenously, and then continued with oral medication for seven days. Anti-tetanus prophylaxis is also given in all cases. In the case of the infected wound, surgical intervention is done only after the clinician is sure that the wound is clinically cleaned.

In terms of treatment outcome, 9.2\% developed hypertophic scar and keloid which were successfully managed with intra lesional injection of kenalog (Triamcinolone). All patients had satisfactory function and aesthetically pleasing appearances after. In the Enugu State study [15], they also had a problem with hypertrophic scar, which was managed using triamcinolone cream.

\section{Conclusion}

Human bite of the orofacial region is still common in our region, and most of the patients assailants were females in their third decade. Interestingly, sexual partners are able to inflict disfiguring human bite on the faces of their partners. Most of the offenders are known to the patients. Majority of the cases, except those infected at the time of presentation, were treated on the same day of presentation under local anaesthesia after they had received antibiotics and anti-tetanus prophylaxis. After repair, patients had a good functional and cosmetic outcome.

\section{Recommendations}

Human bite, even though has a lot of micro-organism contaminations, should be managed differently from animal bites. Early repair is now the recommended mode of treatment for human bites of the orofacial region, accompanied with good oral hygiene instructions and broad spectrum antibiotics and metronidazole.

\section{Limitation of This Study}

The major limitation was that most patients did not come back for review after the repair. Henceit was difficult to evaluate the outcome after six months after which we expected the scare to have matured. The other limitation was that most of the patients were not ready to give additional information concerning the actual cause of the assault especially in cases were the assailant was a sexual partner or rival.

\section{Acknowledgements}

The authors would like to thank the following doctors and nurses who have contributed to the management of orofacial human bites in the Komfo Anokye Teaching Hospital; Dr. Dr. Emmanuel Amponsah, Dr. Solomon Obiri-Yeboah, Dr Samuel Kojo Ansah, Dr. Michael Yelibora, Dr. Robert Nii Lamy Larmie, Dr. Phillipe Pare, Dr. Eva Bernice Wilson, Dr. Nana Tuffuor Ampem Gyimah, Dr. Liza Adjei-Fokuo, Dr. Christian Osei-Bonsu, Lucy Amoateng, Martha Gyasi, Victoria Narh, Barbara Frimpong.

\section{References}

[1] Donkor, P. and Bankas, D.O. (1997) A Study of Primary Closure of Human Bite Injuries to the Face. Journal of Oral and Maxillofacial Surgery, 55, 479-481; Discussion 481-482.

[2] Merchant, R.C., Zabbo, C.P., Mayer, K.H. and Becker, B.M. (2007) Factors Associated with Delay to Emergency Department Presentation, Antibiotic Usage and Admission for Human Bite Injuries. The Journal of Emergency Medicine, 9, 441-448.

[3] Perron, A.D., Miller, M.D. and Brady, W.J. (2002) Orthopedic Pitfalls in the ED: Fight Bite. American Journal of Emergency Medicine, 20, 114-117. http://dx.doi.org/10.1053/ajem.2002.31146

[4] Talan, D.A., et al. (2003) Clinical Presentation and Bacteriologic Analysis of Infected Human Bites in Patients Presenting to Emergency Departments. Clinical Infectious Diseases, 37, 1481-1489. http://dx.doi.org/10.1086/379331

[5] Agrawal, K., Ramachandrudu, T., Hamide, A. and Dutta, T.K. (1995) Tetanus Caused by Human Bite of the Finger. Annals of Plastic Surgery, 34, 201-202. http://dx.doi.org/10.1097/00000637-199502000-00016

[6] Figueirdo, J.F., Borges, A.S., Martinez, R., Martinelli Ade, L., Vilanova, M.G., Covas, D.T., et al. (1994) Transmis- 
sion of Hepatitis C Virus But Not Human Immunodeficiency Virus Type 1 by a Human Bite. Clinical Infectious Diseases, 19, 546-547. http://dx.doi.org/10.1093/clinids/19.3.546

[7] Richman, K.M. and Rickman, L.S. (1993) The Potential for Transmission of Human Immunodeficiency Virus through Human Bites. Journal of Acquired Immune Deficiency Syndromes, 6, 402-406.

[8] Smoot, E.C., Choucino, C.M. and Smoot, M.Z. (2006) Assessing Risks of Human Immunodeficiency Virus Transmission by Human Bite Injuries. Plastic and Reconstructive Surgery, 117, 2538-2539. http://dx.doi.org/10.1097/01.prs.0000219991.22903.eb

[9] Sikora, C.A., Spielman, J., Macdonald, K., Tyrrell, G.J. and Embil, J.M. (2005) Necrotizing Fasciitis Resulting from Human Bites: A Report of Two Cases of Diseases Caused by Group A Streptococcus. Canadian Journal of Infectious Diseases \& Medical Microbiology, 16, 221-224.

[10] Wienert, P., Heiss, J., Rinecker, H. and Sing, A. (1999) A Human Bite. Lancet, 354, 572.

[11] Ball, V. and Younggren, B.N. (2007) Emergency Management of Difficult Wounds: Part 1. Emergency Medicine Clinics of North America, 25, 101-121. http://dx.doi.org/10.1016/j.emc.2007.01.003

[12] Staiano, J. and Graham, K. (2007) A Tooth in the Hand Is Worth a Washout in the Operating Theater. Journal of Trauma-Injury Infection \& Critical Care, 62, 1531-1532. http://dx.doi.org/10.1097/01.TA.0000261348.51768.01

[13] Morgan, M. (2005) Hospital Management of Animal and Human Bites. Journal of Hospital Infection, 61, 1-10. http://dx.doi.org/10.1016/j.jhin.2005.02.007

[14] Chen, E., Horing, S., Shepard, S.M. and Hollander, J.E. (2000) Primary Closure of Mammalian Bites. Academic Emergency Medicine, 7, 157-617.

[15] Olaitan, P.B., Uduezue, A O., Ugwueze, G.C., Ogbonnaya, I.S. and Achebe, U.J. (2007) Management of Human Bites of the Face in Enugu, Nigeria. African Health Sciences, 7, 50-54.

[16] Obukwe, O.N. (2002) A Study of Human Bite Injuries to the Face. Central African Journal of Medicine, 48, 68-71.

[17] Datubo-Brown, D.D. (1988) Management of Human Bites of the Face. Postgraduate Medicine, 10, $233-236$.

\section{Submit or recommend next manuscript to SCIRP and we will provide best service for you:}

Accepting pre-submission inquiries through Email, Facebook, LinkedIn, Twitter, etc.

A wide selection of journals (inclusive of 9 subjects, more than 200 journals)

Providing 24-hour high-quality service

User-friendly online submission system

Fair and swift peer-review system

Efficient typesetting and proofreading procedure

Display of the result of downloads and visits, as well as the number of cited articles

Maximum dissemination of your research work

Submit your manuscript at: http://papersubmission.scirp.org/ 